\title{
Application of Design Structure Matrix (DSM) for Managing Projects on the Basis of Constructability
}

\author{
Sharmin Khan \\ Department of Architecture, Faculty of Engineering \& Technology, Aligarh Muslim University, India
}

Copyright $@ 2016$ by authors, all rights reserved. Authors agree that this article remains permanently open access under the terms of the Creative Commons Attribution License 4.0 International License

\begin{abstract}
Project Management techniques have been developed by many researchers from time to time, to make optimum use of resources. Constructability and Design Structure Matrix are also to be listed among such tools. An attempt has been made in this study to bring together and utilize the best of the management processes to achieve project success. There are mainly two stages of the study. Firstly, construction projects are studied from the point of view of Constructability and a list of thirty activities identified, under three different heads. These activities are then surveyed with a sample group of thirty architects and data regarding their dependency and independency are collected. Based on suitable scores, the data is used to create Design Structure Matrices, which are further processed for iterations, in the second stage. The paper aims to study the advantages of applying DSM to the activities, which are based on the concept of Constructability. The results obtained after the final iterations of DSM, give multidimensional analysis regarding their parallel run, sequencing and networking etc. The DSM's obtained before and after the iterations help prove, that the complex Construction projects can be managed more efficiently after applying DSM.
\end{abstract}

Keywords Integration, Coordination, Standardization, Prefabrication, Recycling, Waste Management

\section{Introduction}

Construction Industry is the biggest industry engaging lot of resources including manpower and energy. There are many challenges faced by Project Managers during the execution of projects. The concept of Constructability was originated by CII as a project management tool to utilize resources in an optimum way. There are principles of Constructability, which are studied for application in the projects. The study needs to be conducted for increasing the efficiency of various activities that are involved in the project, right from the concept development till the final execution on site. On the other hand, Design Structure
Matrix is also emerging as a Management tool to solve issues of dependency and interrelationships. It helps achieving sequencing of activities. The possible combination of both concepts may lead to some feasible solutions that can be applied to the construction projects.

\section{Need of Study}

Constructability is a project management tool which talks about achieving the overall project objectives and focusses on various issues ranging from planning stage to field operations stage. Various activities related to design and constructions influence the working of the project. These activities may be dependent or independent. There is need of organizing these activities according to some hierarchy and occurrence sequence, to be followed. This study is performed to analyze the relationship between different design and construction activities and their sequencing, on the basis of DSM.

\section{Research Questions}

Every research is based on certain questions and objectives. The following study was initiated with the following questions in the mind of the researcher.

- What are the different activities related to design and construction, on the basis of Constructability?

- What are the different heads, in which these activities can be characterized?

- What are the independent activities?

- What activities are dependent? In case they are dependent, then on what other activities?

- What is the sequence/hierarchy in which these activities are related to each other?

\section{Objectives of Study}

The study started with the following objectives:

- To work out various activities related to design and 
construction, based on Constructability parameters.

- To analyze the dependent and independent activities related to design and construction.

- To establish relationship between different design and construction activities, to work out hierarchy and sequence.

\section{The Methodology Adopted for Study}

The research methodology comprises of Literature review, Synthesis of the Literature, Pilot Survey, Data collection through Questionnaire Survey, Data analysis with Design Structure Matrix (DSM) and Recommendations. Different design and construction activities were categorized under three stages of construction project, identified after the literature review. These activities are based on the principles of Constructability. Ten activities were initially placed in each category and Pilot study was performed. The questionnaire drafted was used with a few respondents to determine the need for restructuring, re sequencing, addition or deletion of questions. After incorporating the results of Pilot Survey, the final list of activities was formulated as the basis of Questionnaire survey. This survey was conducted with thirty respondents, practicing in the profession of architecture as well as architecture and project management both, comprising of practitioners and academicians. The survey was conducted manually. Purposive sampling was done. The sample size depended on the availability and willingness of the respondents to spare time for this work. Time and financial constraint were a major guiding factor in collecting responses. The data collected was analyzed for work and tabulated to work out the independent and dependent activities. The final analysis was performed with the help of Design Structure Matrix (DSM). The methodology adopted (Fig.1) is represented as follows:

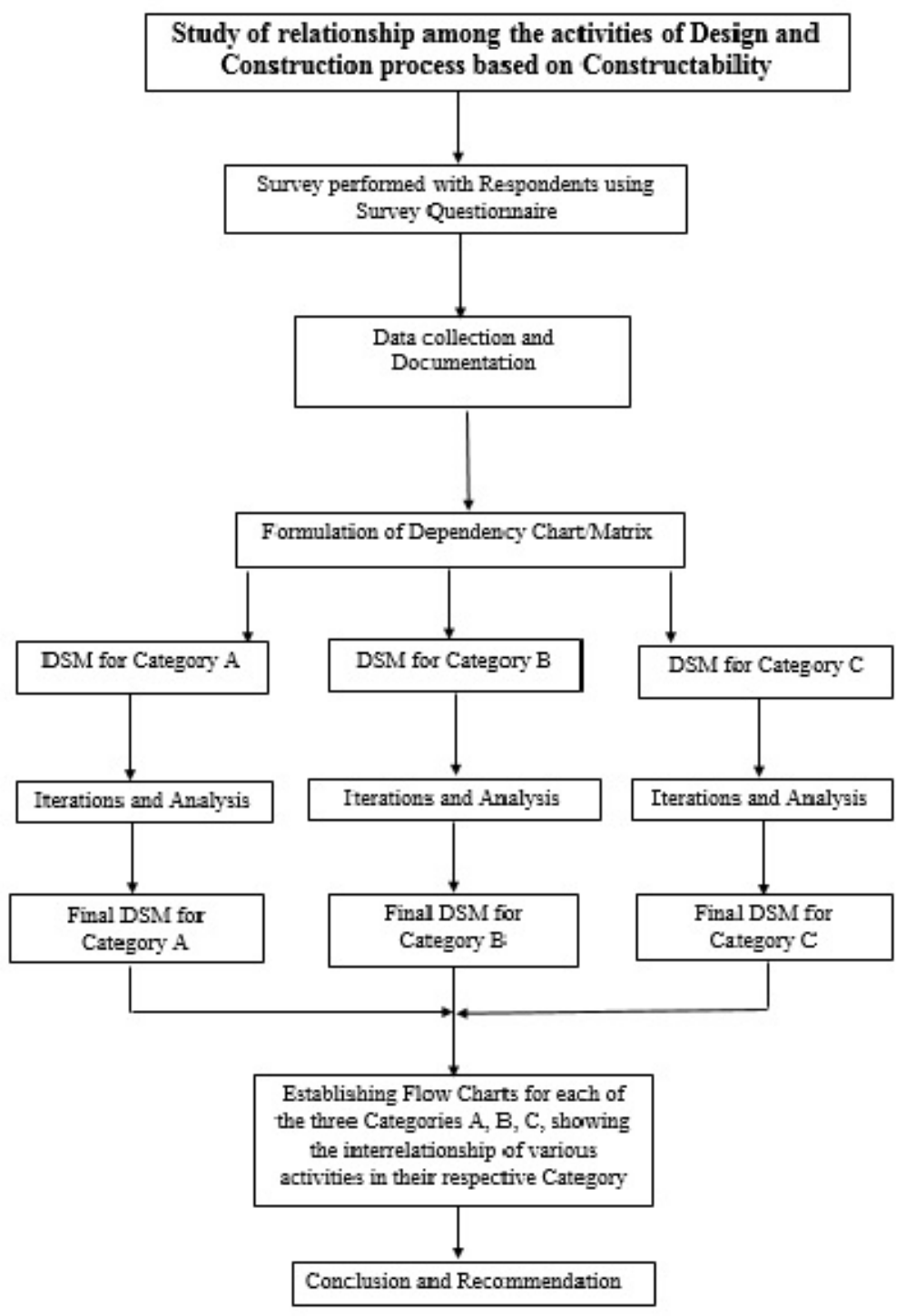

Figure 1. The Research methodology adopted 


\section{Literature Review}

The intensive study of the secondary data available was performed to derive at categorization of design and construction activities. The internet and library of reputed institutes were searched for the secondary data and the work of previous researchers. After exhaustive search the data was compiled to present the literature review.

\section{The Concept of Constructability}

During 1970's, some studies were conducted in United Kingdom and States of America, which aimed at maximizing the efficiency of construction projects, through the concept of constructability. The Construction Industry Research and Information Association (CIRIA) laid emphasis on design process and early involvement of construction expertise. The concept of constructability was very well promoted by Construction Industry Institute (CII), in US. They also formulated guidelines for its implementation (Wong et al., Trigunarsyah ) [1, 2].

CII has defined Constructability as "the optimum use of construction knowledge and experience in planning, engineering, procurement and field operations to achieve overall project objectives" (CII, 1986) [3]. The ability to influence the cost of project decreases with time, hence there is maximum scope in the beginning of the project to consider issues that can affect cost.

Glavinich [4] describes constructability of a design as, "the ease with which the raw materials of the construction process (labour, production, equipment, tools, materials and installed equipment) can be brought together by a builder to complete the project in a timely and economic manner”. O’Connor et al. [5] have presented and analyzed seven concepts for improving constructability during engineering and procurement phase of the project. These concepts are: Construction driven schedule, Simplified designs, Standardization, Module engineering, Accessibility, Adverse weather and Specifications.

\section{Principles of Constructability}

Among various other principles the involvement of construction knowledge in conceptual planning stage is the most important and basic principle. CII Australia proposed twelve principles for execution of the constructability programme. These principles are Integration, Construction knowledge, Team skills, corporate objectives, Available resources, and External factors, Programmer, Construction Methodology, Accessibility, Specifications, Construction Innovation and Feedback. Tatum (1987) investigated fifteen projects and identified three key issues during conceptual planning stage: developing the project plan, laying out the site and selecting major construction methods. These issues were found beneficial in improving constructability [6]. Radtke (1992) paper outlined research looking at constructability practices to integrate the construction knowledge into design and planning phases of project. These methodologies may be either formal or informal ways.
Formal ways are identified as documentation, tracking through past lessons learned, and team building exercises and the participation of construction personnel in project planning. The informal ways be like design reviews and inclusion of construction coordinators [7]. Pocock et al. (1996) presented that one of the "critical factors" identifying successful projects in "constructability information from and available to the project team in a timely manner" [8]. Constructability programme implementations have resulted in significant gains in safety performance, schedule and project cost control (Jergeas and Put 2001) [9]. Pulaski and Horman (2005) introduced a model CPPMM - Conceptual Product/Process Matrix Model, for organizing constructability information based on timings and levels of detail. They concluded that, "the key to accessing constructability is introducing the right information at the right time and in the right level of detail” [10].

\section{Synthesis of Literature Review}

After performing literature review, the major issues have been extracted from the research of various authors and organized under various heads. The issues have been taken which were common to most of the papers and the viewpoints gathered thereof. These sixteen issues can be listed as: Integration, Coordination, Bidding Process, Construction driven schedule, Simplification of Design, Standardization of element, Prefabrication, Accessibility to Site, Adverse weather conditions, Specifications, Encouragement to Innovations, Past Lessons Learned Exercise \& Reviews, Availability of Resources, Use of Recycling for different materials, Waste Management, Application of Advance Information Technology. On the basis of this information, the design and construction activities were categorized in three groups, each having ten activities. The categories are, Category A - Conceptual planning stage, Category B - Design development stage and Category C - Field operations stage.

\section{Data Collection and Survey}

The three categories identified after the literature review were used for further study and analysis. The modifications and restructuring of the activities after Pilot Survey resulted in the following categorization of activities.

\section{Category A - Conceptual Planning Stage}

1. Selection of Architect

2. Shortlisting of Contractors

3. Discussion on how to make construction process easier

4. Conducting surveys

5. Selection of Construction methods

6. Working out Construction Schedule

7. Laying out site efficiently

8. Discussion on recycling 
9. Simplification of technical specifications

10. Review and implementation of past lessons learned

\section{Category B - Design Development Stage}

1. Development of Design and Procurement schedule

2. Selection of Contractor

3. Selection of Subcontractors/ vendors

4. Use of advance information technology

5. Standardization of design elements

6. Review of design by other team members

7. Small scale physical models/ 3 D drawings

8. Considerations for site drainage

9. Considerations for water conservation

10. Concern to reduce scaffolding

11. Preference of methods/ materials for renovation and deconstruction

12. Consideration for environmentally safe materials/ methods of construction

\section{Category C - Field Operations Stage}

1. Field task sequencing (CPM etc.)

2. Use of temporary material/system on site

3. Innovation in available equipment

4. Freedom to contractors for technical inputs to improve the construction process

5. Use of preassembly in case of adverse weather

6. Documentation work of the lessons learned during the project execution stage

7. Waste management on site

8. Regular inspection/meetings on/off site by consultants

The above mentioned activities were framed in a questionnaire and surveyed with a sample of thirty professionals. The respondents were requested to state whether each of the activities mentioned was dependent or independent in its own category i.e. A, B and C. In case the activity was dependent, the respondents were requested to mention the activities on which they depended. The results were then used to calculate the dependency and independency of various activities. The data was later transferred in the Design Structure Matrix for each of the categories and analyzed.

\section{Data Analysis Using DSM}

The data collected from Survey, was analyzed using Design Structure Matrix (DSM). A Design Structure Matrix (DSM) is defined as a compact, matrix representation of a project network. A DSM provides an idea about various activities of any process that are interrelated, what information is required to start an activity, what activity will be followed by any previous activity, manages complex projects, does task sequencing and iterations (Yassine) [11]. Steward [12] has also defined DSM as "a methodology to handle dependencies and relations between items". Browning (2001b) [13] explains that "DSM is a representation and analysis tool for the system modelling. A DSM displays the relationships between components of a system in a compact, visual and analytically advantageous format”.

A DSM is also known as "Dependency Structure Matrix" (Danilovic and Browning, 2007) [14]. However there are other terms also like the Problem Solving Matrix (PSM) and Design Precedence Matrix. It is a management tool applied in Project Management. It provides a project representation that allows for feedback and cyclic task dependencies [15]. A DSM is a square matrix having identical rows and column labels. The diagonal is shaded. There are marks on the off diagonal, which show the interrelationships.

\section{Columns $=$ Input sources and Rows $=$ Output sinks.}

Yassine [11] explains that all the marks above the diagonal are feedback marks. The Feedback marks are the required input that is not available at the time of executing a task. These inputs are assumed which can be raised later. It is advisable to reduce these feedback marks. A DSM cannot show all the aspects at a glance like Gantt chart or flow chart but it conveniently highlights iteration and rework. Browning (2002) explains that after a DSM is prepared, the marks that are below the diagonal are the key drivers of cost and schedule risks [16]. Browning, T. R. and Eppinger (2002) state that DSM provides as easy way to document potential "process failure modes" and their effect on other activities. The binary marks can be replaced by numbers that reflect relative probability of information change, iterations etc. [17].

\section{Types of Design Structure Matrix}

Browning (2001a) elaborates that there are two main categories of DSM [18]. These are Static DSM and Time based DSM.

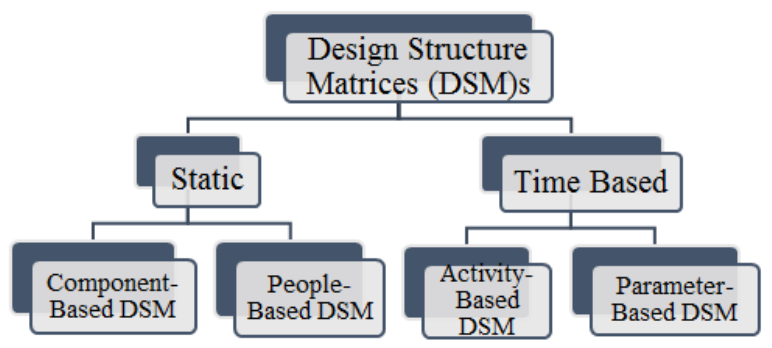

Figure 2. The types of DSM

The Static DSM can further be classified into Component Based and People Based DSMs. Whereas the Time Based DSM can be classified as Activity Based and Parameter Based DSMs (Fig.2.) In case of Static DSM, the system elements exist simultaneously whereas in Time Based DSM, the ordering indicates flow through time.

This study is focused on Activity Based DSM. These are used for modelling processes and activity networks based on activities, their information flow and other dependencies. 


\section{Creating Design Structure Matrix}

Yassine [1] has defined the following steps that can be adopted for creating a DSM.

Stage 1 - Building/Creating the Design Structure Matrix

- Decompose the system into components/activities. (With the help of existing documentation or structured expert interviews). As a result we get a Set of Activities.

- Expert opinion about inputs, outputs and strength of interactions. As a result we get the Dependency and Independency of various activities.

- Enter marks in the Design Structure Matrix (x or •)

Stage 2- Project Redesign

- Partitioning - (Reordering) such that feedback marks eliminated/reduced/closer to the diagonal.

- Tearing - Choose feedback marks that if removed from matrix will render matrix lower triangular. The removed marks are called tears.

- DSM Banding - Addition of light and dark bands to show independent (parallel or concurrent) activities. (Grose,1994) [19].

- Clustering - Forms subsets that are mutually exclusive. These are team formations or independent modules. (Sharman and Yassine, Yu et al [20, 21].

Steward [12] explained about tearing that the least damaging assumptions are made first and their marks are temporarily removed or "torn” from DSM. The block is then repartitioned. In case sub diagonal marks remain, the next least damaging assumptions are made. The process is repeated till no feedback marks remain.

Yu et al. [21] added that in the process of clustering, the interactions or links between separate clusters is eliminated or minimized. Several clustering techniques may lead to optimal solutions under certain assumptions. Eppinger [22] elaborates about numeric DSM as an extension for binary DSM, using numbers in the off diagonal entries. The numbers are used in such a manner that they represent the strength of dependencies, in ease of making assumptions etc. However in his paper He also suggested certain level numbers for " $x$ " marks. According to him, the numbers can be chosen as; $1=$ high dependency, 2= medium dependency, 3= low dependency. In such cases, the lower dependency marks are to be teared first.

\section{The Result of Survey Study}

The study conducted on a sample of thirty is presented in the form of dependency matrix for each of the three categories; A, B and C.

The results obtained were used to prepare DSM for each of the 3 categories- A, B and C. The activities with least dependency score were neglected for the purpose of study as these had a range from 0-7 as compared to the Highest Dependency score, which was 23-30. The scores which were included in the study were for Partially Dependent, Moderately Dependent and Highly Dependent activities. (Table 1, 2, 3) 
Table 1. Dependency Matrix for Category A

Category A - CONCEPTUAL PLANNING STAGE

\begin{tabular}{|c|c|c|c|c|c|c|c|c|c|c|c|c|c|}
\hline \multicolumn{14}{|c|}{ Category A - CONCEPTUAL PLANNING STAGE } \\
\hline \multirow[b]{2}{*}{ S. No. } & \begin{tabular}{|c|} 
S. No. \\
\end{tabular} & 1 & 2 & 3 & 4 & 5 & 6 & 7 & 8 & 9 & 10 & & \\
\hline & Activities & $\begin{array}{c}\text { Selection of } \\
\text { Architect }\end{array}$ & $\begin{array}{c}\text { Shortlisting } \\
\text { of } \\
\text { Contractors }\end{array}$ & $\begin{array}{c}\text { Discussion on How } \\
\text { to make construction } \\
\text { process easier }\end{array}$ & $\begin{array}{l}\text { Conducting } \\
\text { surveys }\end{array}$ & $\begin{array}{c}\text { Selection of } \\
\text { Construction } \\
\text { methods }\end{array}$ & $\begin{array}{c}\text { Working out } \\
\text { Construction } \\
\text { Schedule }\end{array}$ & $\begin{array}{c}\text { Laying out site } \\
\text { efficiently }\end{array}$ & \begin{tabular}{|c|} 
Discussion on \\
recycling
\end{tabular} & $\begin{array}{c}\text { Simplification of } \\
\text { technical } \\
\text { specifications } \\
\end{array}$ & $\begin{array}{c}\text { Review and } \\
\text { implementation of } \\
\text { past lessons leamed }\end{array}$ & & \\
\hline 1 & Selection of Architect & & & & & 0 & & & & & & 0 & Least Dependent \\
\hline 2 & Shortlisting of Contractors & - & & 0 & & 0 & 0 & - & 0 & & 0 & - & Partially Dependent \\
\hline 3 & $\begin{array}{l}\text { Discussion on How to make } \\
\text { construction process easier }\end{array}$ & - & - & & 0 & - & ? & 0 & 0 & 0 & - & - & Moderately Dependent \\
\hline 4 & Conducting surveys & - & 0 & & & & 0 & & 0 & & - & $\bullet$ & Highly Dependent \\
\hline 5 & $\begin{array}{l}\text { Selection of Construction } \\
\text { methods }\end{array}$ & - & - & - & & & 0 & $\bullet$ & & $\theta$ & 0 & & \\
\hline 6 & $\begin{array}{l}\text { Working out Construction } \\
\text { Schedule }\end{array}$ & $\bullet$ & - & $\bullet$ & & - & & & & 0 & 0 & & \\
\hline 7 & Laying out site efficiently & - & 0 & $\theta$ & \% & - & 0 & & & & 0 & & \\
\hline 8 & Discussion on recycling & $\bullet$ & $\bullet$ & $\bullet$ & & 0 & & & & 0 & $\theta$ & & \\
\hline 9 & Simplification of Technical Spec. & - & $\bullet$ & & & $\bullet$ & & & 0 & & & & \\
\hline 10 & $\begin{array}{c}\text { Review and implementation of } \\
\text { past lessons leamed }\end{array}$ & 0 & ○ & 0 & 0 & (-) & & & 0 & & & & \\
\hline
\end{tabular}


Table 2. Dependency Matrix for Category B

\begin{tabular}{|c|c|c|c|c|c|c|c|c|c|c|c|c|c|}
\hline \multirow[b]{3}{*}{ S. No. } & \multicolumn{13}{|c|}{ Category B -DESIGN DEVELOPMENT STAGE } \\
\hline & \begin{tabular}{|l|l|} 
S. No. \\
\end{tabular} & \begin{tabular}{|l|}
1 \\
\end{tabular} & 2 & 3 & 4 & 5 & 6 & 7 & 8 & 9 & 10 & 11 & 12 \\
\hline & Activities & $\begin{array}{c}\text { Development of } \\
\text { Design and } \\
\text { Procurement } \\
\text { schedule }\end{array}$ & $\begin{array}{l}\text { Selection of } \\
\text { Contractor }\end{array}$ & $\begin{array}{c}\text { Selection of } \\
\text { Subcontractor } \\
\text { si vendors }\end{array}$ & $\begin{array}{l}\text { Use of } \\
\text { advance } \\
\text { information } \\
\text { technology }\end{array}$ & $\begin{array}{c}\text { Standardizatio } \\
\text { nof design } \\
\text { elements }\end{array}$ & $\begin{array}{c}\text { Review of } \\
\text { design by } \\
\text { other team } \\
\text { members }\end{array}$ & $\begin{array}{l}\text { Small scale } \\
\text { physical } \\
\text { models/30 } \\
\text { drawings }\end{array}$ & $\begin{array}{c}\text { Consideratio } \\
\text { nsfor site } \\
\text { drainage }\end{array}$ & $\begin{array}{c}\text { Consideration } \\
\text { sfor water } \\
\text { conservation }\end{array}$ & $\begin{array}{l}\text { Concernto } \\
\text { reduce } \\
\text { scaffolding }\end{array}$ & $\begin{array}{l}\text { Prefernce of } \\
\text { methodsl } \\
\text { materials for } \\
\text { renovation and } \\
\text { deconstruction }\end{array}$ & $\begin{array}{l}\text { Consideration for } \\
\text { environmentally } \\
\text { safe materialsl } \\
\text { methods of } \\
\text { construction }\end{array}$ \\
\hline 1 & \begin{tabular}{|l|} 
Development of Design \\
and Procurement schedule
\end{tabular} & & 0 & 0 & 0 & 0 & 0 & 0 & ○ & 0 & 0 & - & 0 \\
\hline 2 & Selection of Contractor & & & & 0 & & & & & & 0 & - & 0 \\
\hline 3 & $\begin{array}{l}\text { Selection of } \\
\text { Subcontractors/ vendors }\end{array}$ & 0 & O & & 0 & & & & & & & 0 & 0 \\
\hline 4 & $\begin{array}{l}\text { Use of advance information } \\
\text { technology }\end{array}$ & 0 & 0 & 0 & & & & 0 & 0 & 0 & & & \\
\hline 5 & $\begin{array}{l}\text { Standardization of design } \\
\text { elements }\end{array}$ & 0 & 0 & 0 & & & & & & & $\bullet$ & - & \\
\hline 6 & $\begin{array}{l}\text { Review of design by other } \\
\text { team members }\end{array}$ & 0 & 0 & 0 & & & & & & & & & \\
\hline 7 & $\begin{array}{l}\text { Small scale physical } \\
\text { models/30 drawings }\end{array}$ & 0 & 0 & & 0 & & 0 & & 0 & 0 & & & \\
\hline 8 & $\begin{array}{l}\text { Considerations for site } \\
\text { drainage }\end{array}$ & & 0 & 0 & 0 & & & 0 & & & & & 0 \\
\hline 9 & $\begin{array}{l}\text { Considerations for water } \\
\text { conservation }\end{array}$ & 0 & 0 & 0 & 0 & & & 0 & 0 & & & & 0 \\
\hline 10 & $\begin{array}{l}\text { Concern to reduce } \\
\text { scaffolding }\end{array}$ & - & 0 & 0 & 0 & $\bullet$ & & & & & & & 0 \\
\hline 11 & \begin{tabular}{|l|} 
Prefernce of methodsl \\
materials for renovation and \\
deconstruction
\end{tabular} & 0 & 0 & 0 & 0 & 0 & - & & & & & & 0 \\
\hline 12 & $\begin{array}{l}\text { Consideration for } \\
\text { environmentally safe } \\
\text { materialsi methods of } \\
\text { construction }\end{array}$ & & $\bullet$ & 0 & 0 & & $\bullet$ & & & 0 & & & \\
\hline
\end{tabular}

$\bullet$

Partially Dependent

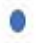
Moderately Dependent

- 
Table 3. Dependency Matrix for Category C

\begin{tabular}{|c|c|c|c|c|c|c|c|c|c|}
\hline S. No. & \multicolumn{3}{|c|}{ Category C - FIELD OPERATIONS STAGE } & 3 & 4 & 5 & \begin{tabular}{|c|}
6 \\
Documentation \\
work of the \\
lessons learned \\
during the \\
project execution
\end{tabular} & 7 & 8 \\
\hline 1 & $\begin{array}{l}\text { Field task sequencing } \\
\text { (CPM etc.) }\end{array}$ & & 0 & ○ & ○ & ○ & O & 0 & 0 \\
\hline 3 & $\begin{array}{c}\text { Innovation in available } \\
\text { equipment }\end{array}$ & & 0 & & - & & 0 & - & 0 \\
\hline 4 & $\begin{array}{l}\text { Freedom to contractors } \\
\text { for technical inputs to } \\
\text { improve the } \\
\text { construction process }\end{array}$ & & & 0 & & & & & ○ \\
\hline 6 & $\begin{array}{c}\text { Documentation work of } \\
\text { the lessons learned } \\
\text { during the project } \\
\text { execution stage }\end{array}$ & & ? & ○ & & & & 0 & 0 \\
\hline 7 & $\begin{array}{l}\text { Waste management on } \\
\text { site }\end{array}$ & 0 & & 0 & - & & ○ & & 踝 \\
\hline 8 & $\begin{array}{c}\text { Regular } \\
\text { inspection/meetings } \\
\text { on/off site by } \\
\text { consultants } \\
\end{array}$ & ○ & - & & ○ & 0 & 0 & ○ & \\
\hline
\end{tabular}

Least Dependent

○

Partially Dependent

-

Moderately Dependent

Highly Dependent 


\section{Application of DSM to Category- A}

The category A has a set of ten activities (Table 4). The dependency of activities was already measured through survey. The activities which are least dependent are not considered for making matrix. The remaining dependency chart is as below:

Table 4. List of activities in Category A and their relationship with other activities

\begin{tabular}{|c|l|c|}
\hline S. No. & & \multicolumn{1}{|c|}{ Activity } \\
\hline $\mathbf{1}$ & Selection of Architect & Depends on the Activity \\
\hline $\mathbf{2}$ & Shortlisting of Contractors & $\mathbf{1 , 5}$ \\
\hline $\mathbf{3}$ & Discussion on how to make construction process easier & $\mathbf{1 , 2 , 5 , 1 0}$ \\
\hline $\mathbf{4}$ & Conducting surveys & $\mathbf{1 , 2 , 3 , 7}$ \\
\hline $\mathbf{5}$ & Selection of Construction methods & $\mathbf{1 , 2 , 3 , 5}$ \\
\hline $\mathbf{6}$ & Working out Construction Schedule & $\mathbf{1 , 4 , 5}$ \\
\hline $\mathbf{7}$ & Laying out site efficiently & $\mathbf{1 , 2 , 3}$ \\
\hline $\mathbf{8}$ & Discussion on recycling & $\mathbf{1 , 2 , 5}$ \\
\hline $\mathbf{9}$ & Simplification of technical specifications & Independent \\
\hline $\mathbf{1 0}$ & Review and implementation of past lessons learned & \\
\hline
\end{tabular}

The black cells represent the diagonal.

The independent and dependent activities are represented in the Design Structure Matrix (Fig.3).

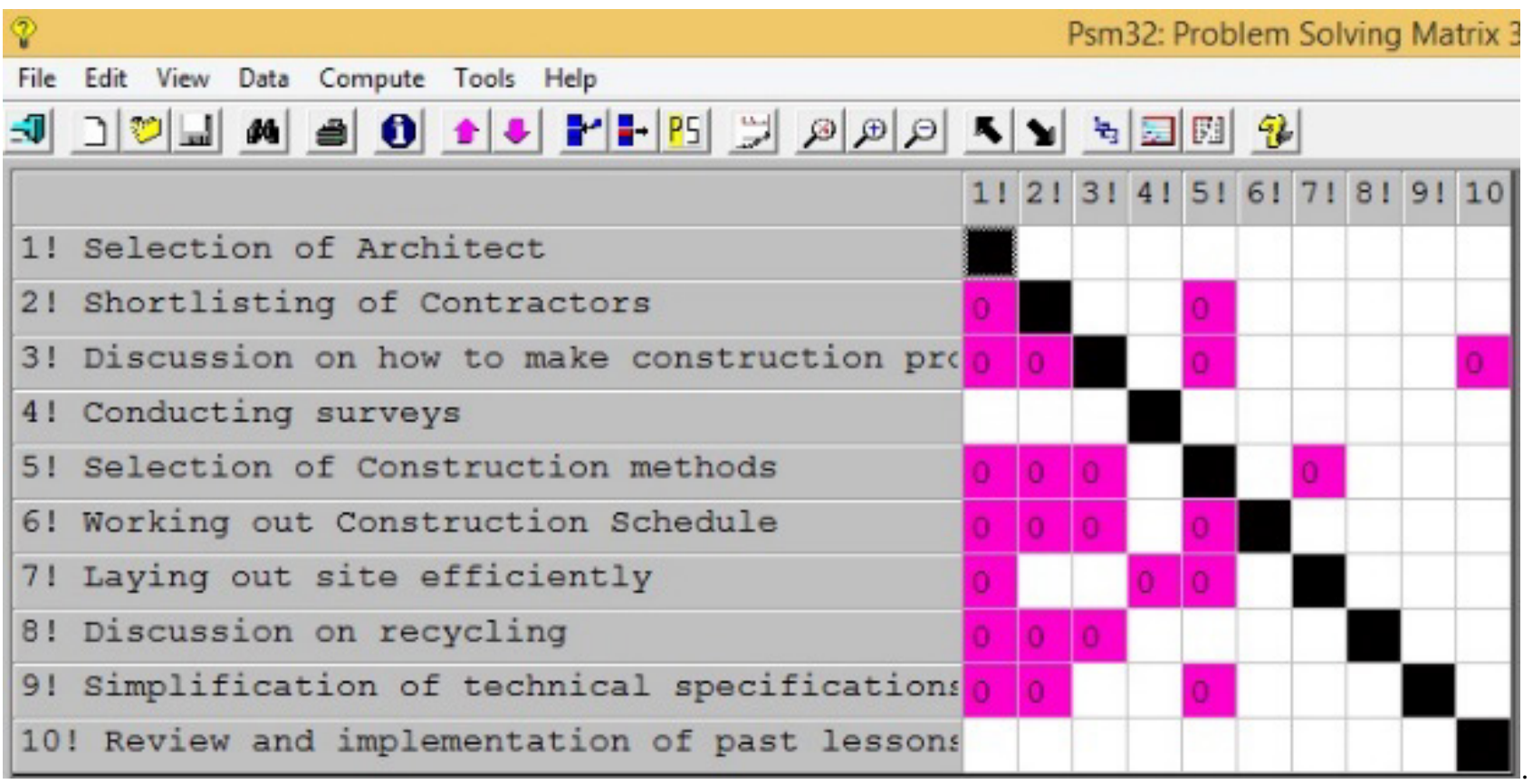

Figure 3. The Original DSM for Category A

\section{The DSM after First Partitioning}

The first partitioning rearranges the items and creates a BLOCK of activities that are grouped together (Fig.4.). These are coupled activities. Except the BLOCK all the items appear below the diagonal. The marks above the diagonal show the assumptions. They control the iterations if assumptions are not valid. The marks below the diagonal provide a Critical Path network, if all assumptions are valid.

The items 1,4 and 10 can be started immediately as they have no predecessors.

The items 2, 3, 5 and 7 all depend on each other, so they are a BLOCK and there is no place to start.

Item 6 can be started after item 1,2,3,5 are performed.

Item 8 can be started after item 1, 2, 3 are performed.

Item 9 can be started after item 1, 2, 5 are performed. 


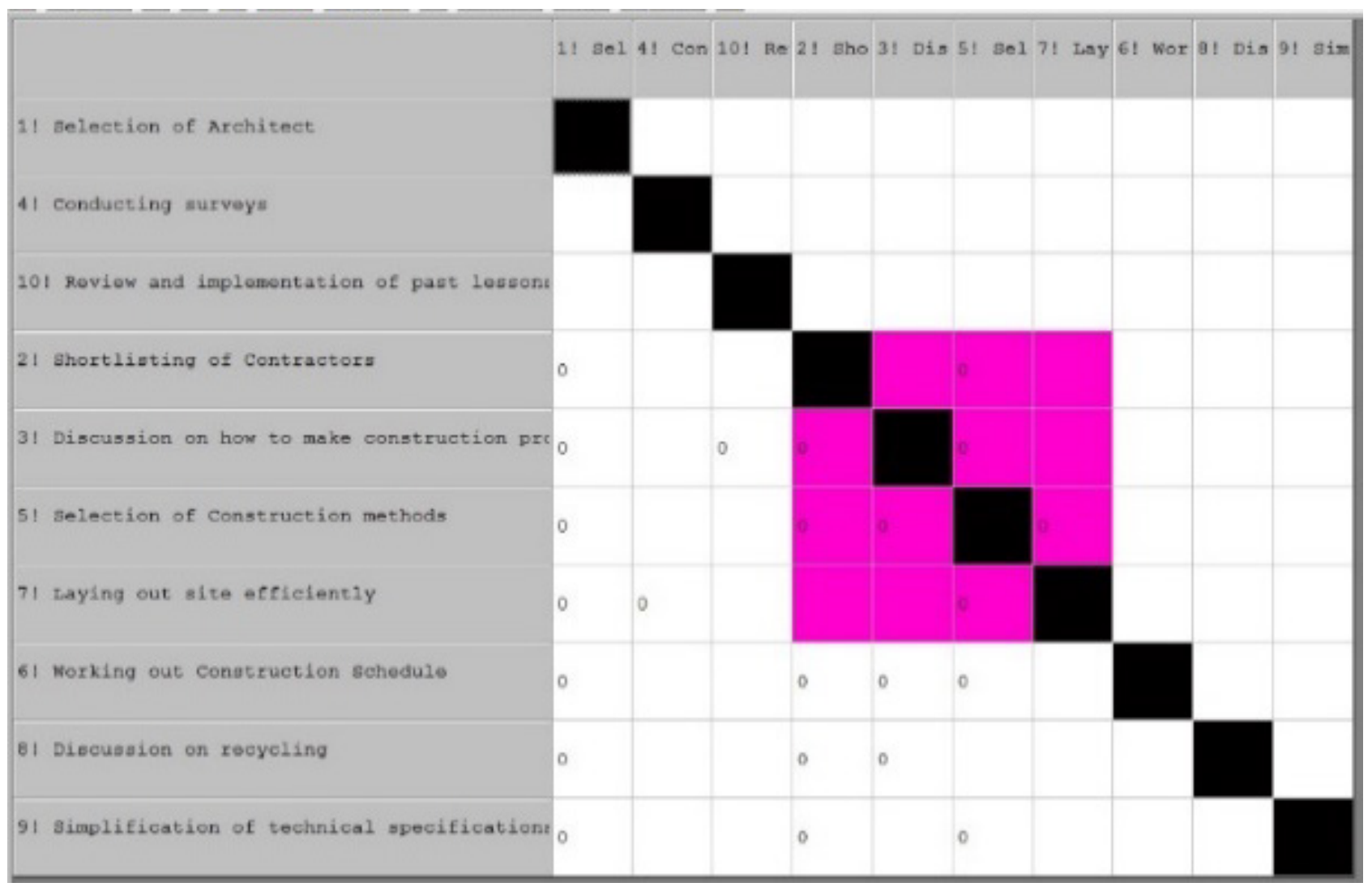

Figure 4. The Partitioned DSM showing the BLOCK- Category A

\section{Principal Circuit}

The yellow squares (with + signs) form the principal circuit, that forms the long circuit (Fig. 5.). The longest circuit is comprised of item $2,3,5$. The tearing advice window shows WS $=0.000$, for item 5 . This is the circuit to be torn. The value 9 is fed in the mark item 5 windows, for identifying the tear. This replaces every mark, wherever tear is required, with number 9, within the BLOCK.

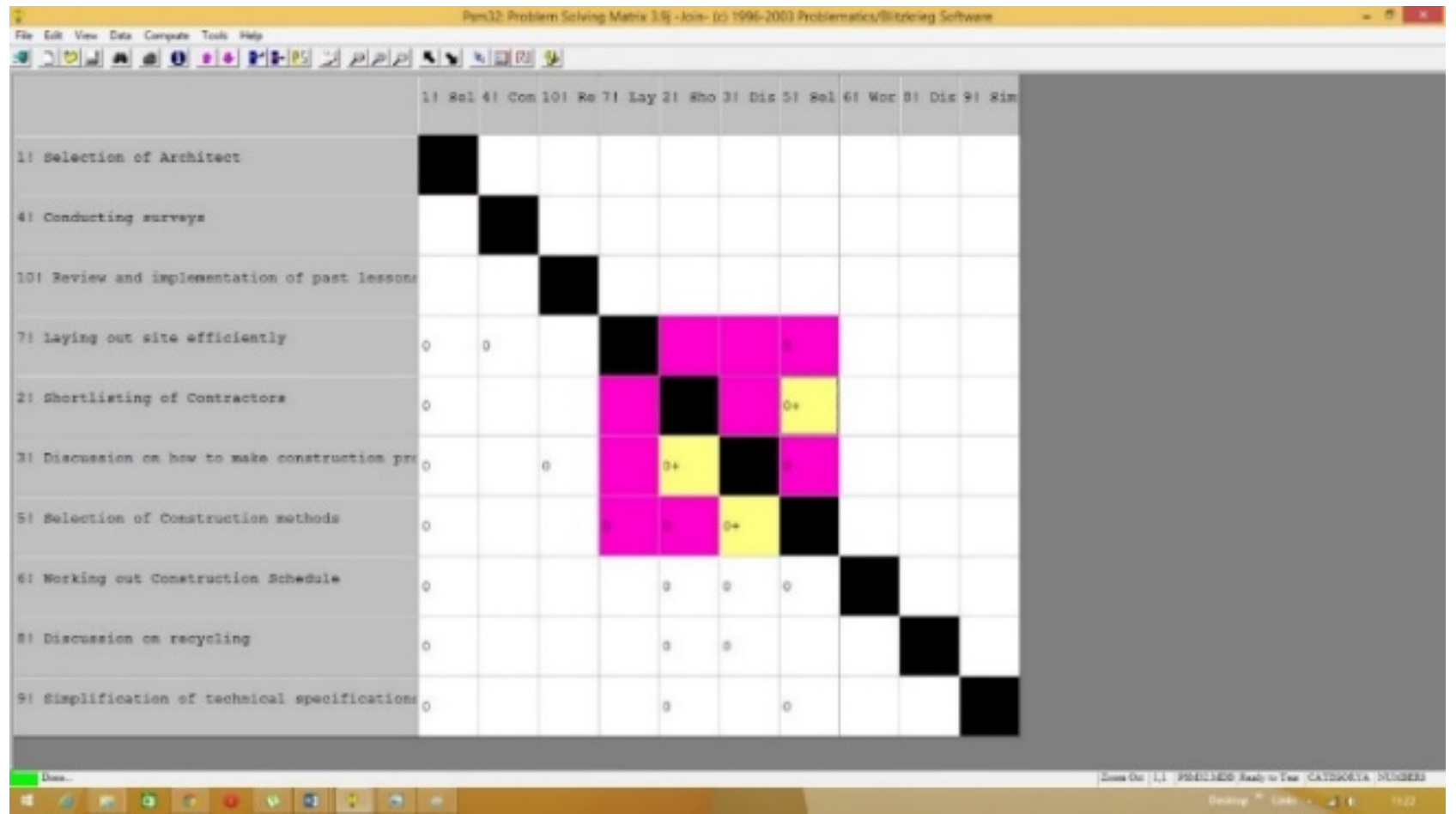

Figure 5. The DSM showing Principal Circuit - Category A 


\section{After Tearing the Circuit and Partitioning}

The matrix rearranges itself after tearing the circuit and a new matrix is formed after partitioning. There appears no 0 mark above the diagonal. All the 0 marks are shifted below the diagonal. Hence this is the final matrix obtained (Fig.6.).

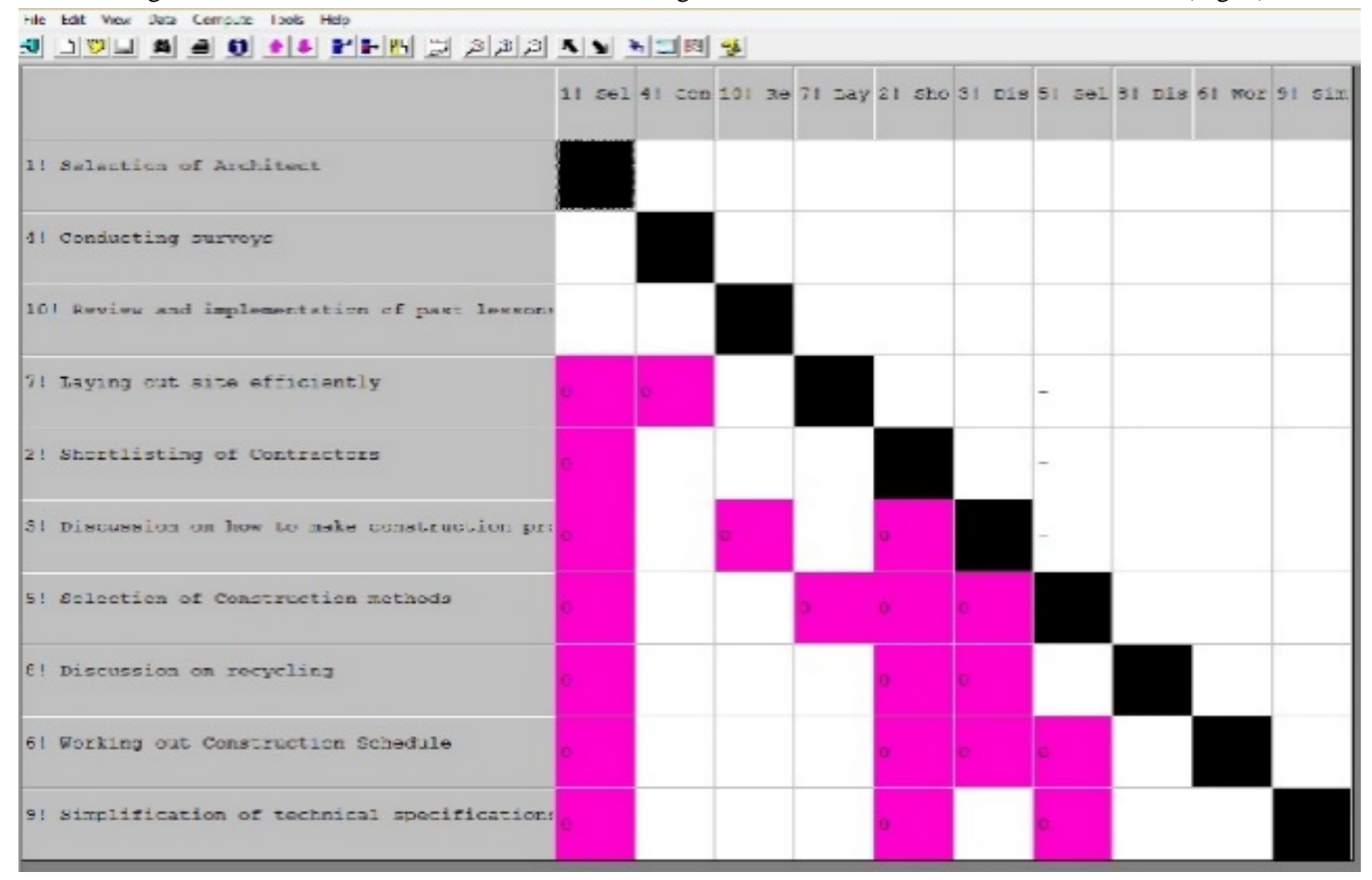

Figure 6. The Final DSM - Category A

\section{Analysis of Category and Activities after Iterations}

The final DSM has all the activities below the diagonal. Item $1,4,10$ can start immediately as they have no predecessors. This interprets as; Selection of Architect, Conducting Surveys and Review and Implementation of Past lessons Learned can be started immediately. The DSM notified rows that give a series of activities that can be performed. After Item 1,4,10, the next activities that can start are Item 7 and 2 . These activities can be done simultaneously by assigning them to different people i.e. Laying out site efficiently and Shortlisting of Contractors. Following these, Item 3 can take place i.e. Discussion on how to make Construction process easier. This shall be followed by Item 5 and 8. i. e. Selection of Construction methods and Discussion on recycling can be done simultaneously.

\section{Impact Analysis}

The final DSM is studied for impacts. The purpose of this study is to identify the impact of an activity on other activities. The following analysis has been done by the DSM.

- Selection of Architect has an impact on laying out site efficiently, Shortlisting of Contractors, Discussion on how to make construction process easier, Selection of Construction methods, Discussion on recycling,
Working out Construction Schedule and Simplification of technical specifications.

- Conducting surveys has an impact on laying out site efficiently.

- Review and implementation of past lessons learned has an impact on Discussion on how to make construction process easier.

- Laying out site efficiently has an impact on Selection of Construction methods.

- Shortlisting of Contractors has an impact on Discussion on how to make construction process easier, Selection of Construction methods, Discussion on recycling, Working out Construction Schedule, and Simplification of technical specifications.

- Discussion on how to make construction process easier has an impact on Selection of Construction methods, Discussion on recycling and Working out Construction Schedule.

- Selection of Construction methods has an impact on Working out Construction Schedule and Simplification of technical specifications.

- Discussion on recycling, Simplification of technical specifications and Review and implementation of past lessons learned have no impact on any other activity in Category A i.e. Conceptual Planning Stage. 


\section{Parallel Activities Analysis}

The DSM shows the parallel activities also.

- Selection of Architect, Conducting Surveys, Review and implementation of past lessons learned, Discussion on how to make construction process easier, Working out Construction schedule and Simplification of technical specifications are grouped together.

- Laying out site efficiently, Shortlisting of Contractors, Selection of Construction Methods and Discussion on recycling are all grouped together.

\section{Dependent Activities Analysis}

The final DSM has activities which are independent and dependent. These can be planned as worked out. These can also be used for preparing CPM networks for the activities. The activities which have been identified by DSM as independent activities are; Selection of Architect, Conducting Surveys and Review and Implementation of Past lessons Learned.

- Laying out site efficiently depends on Selection of Architect and conducting surveys.

- Shortlisting of contractors depends on Selection of Architect.

- Discussion on how to make construction process easier depends on Selection of Architect, Shortlisting of contractors and Review and implementation of past lessons learned.

- Selection of Construction Methods depends on Selection of Architect, Shortlisting of contractors, Discussion on how to make construction process easier and Laying out site efficiently.

- Discussion on recycling depends on Selection of Construction Methods, Selection of Architect,
Shortlisting of contractors and Discussion on how to make construction process easier.

- Working out Construction schedule depends on Selection of Architect, Shortlisting of contractors, and Discussion on how to make construction process easier and Selection of construction methods.

- Simplification of technical specifications depends on Selection of Architect, Shortlisting of contractors and Selection of construction methods.

\section{Application of DSM to Cat- B}

Table 5. List of activities in Category B and their relationship with other activities

\begin{tabular}{|c|l|c|}
\hline $\begin{array}{c}\text { S. } \\
\text { No. }\end{array}$ & \multicolumn{1}{|c|}{ Activities } & $\begin{array}{c}\text { Depends on the } \\
\text { Activity }\end{array}$ \\
\hline $\mathbf{1}$ & $\begin{array}{l}\text { Development of Design and Procurement } \\
\text { schedule }\end{array}$ & Independent \\
\hline $\mathbf{2}$ & Selection of Contractor & Independent \\
\hline $\mathbf{3}$ & Selection of Subcontractors/ vendors & $\mathbf{2}$ \\
\hline $\mathbf{4}$ & Use of advance information technology & Independent \\
\hline $\mathbf{5}$ & Standardization of design elements & $\mathbf{1 0 , 1 1}$ \\
\hline $\mathbf{6}$ & Review of design by other team members & Independent \\
\hline $\mathbf{7}$ & Small scale physical models/3 D drawings & Independent \\
\hline $\mathbf{8}$ & Considerations for site drainage & Independent \\
\hline $\mathbf{9}$ & Considerations for water conservation & Independent \\
\hline $\mathbf{1 0}$ & Concern to reduce scaffolding & $\mathbf{1 , 2 , 5}$ \\
\hline $\mathbf{1 1}$ & $\begin{array}{l}\text { Preference of methods/ materials for } \\
\text { renovation and deconstruction }\end{array}$ & $\mathbf{6}$ \\
\hline $\mathbf{1 2}$ & $\begin{array}{l}\text { Consideration for environmentally safe } \\
\text { materials/ methods of construction }\end{array}$ & $\mathbf{2 , 6}$ \\
\hline
\end{tabular}

The category B has a set of twelve activities (Table 5). The dependency of activities has already been measured with the help of survey. The activities which are least dependent are not considered for making matrix. The remaining dependency chart is as above: 
The independent and dependent activities are represented in the Design Structure Matrix (Fig.7.).

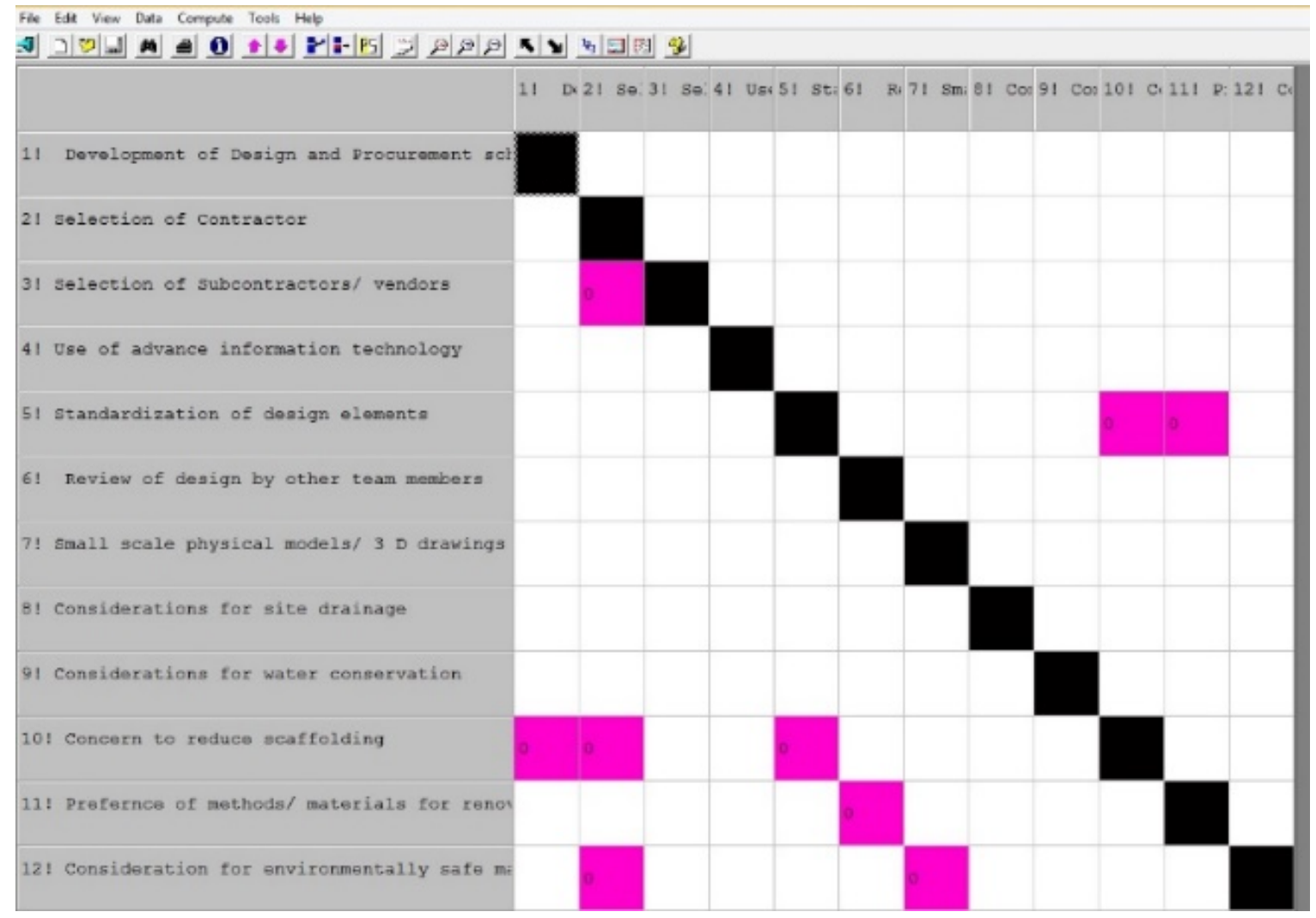

Figure. 7. The original DSM for Category B

The DSM after First Partitioning

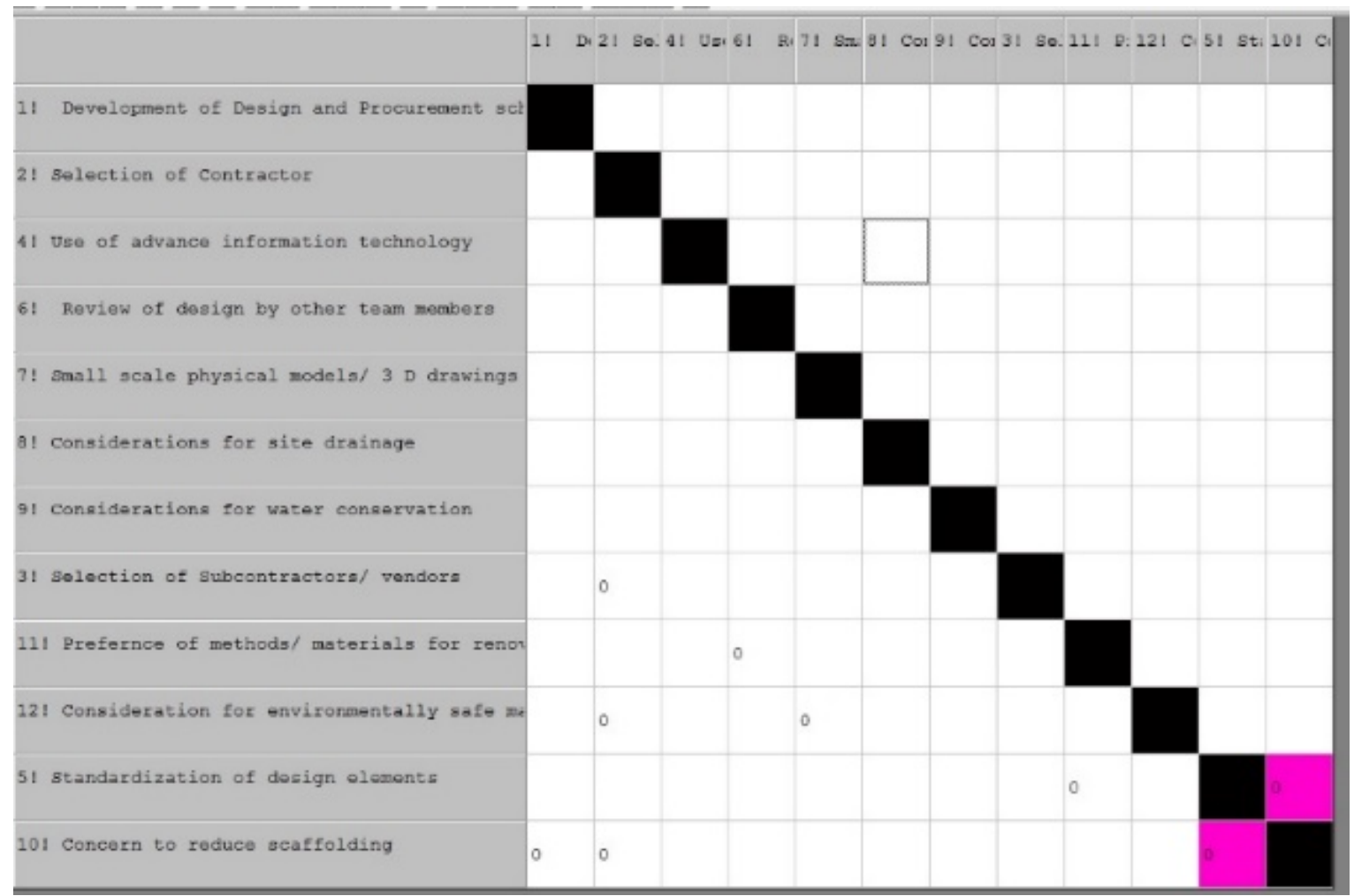

Figure. 8. The DSM showing Principal Circuit - Category B 
The first partitioning rearranges the items and creates a BLOCK of activities that are grouped together (Fig. 8.) These are coupled activities. The data can be read on the previous concept as mentioned for Category A.

The items 1, 2, 4, 6, 7, 8, 9 can be started immediately as they have no predecessors.

Item 3 can be started after item 2 is performed.

Item 11 can be started after item 6 is performed.

Item 12 can be started after item 2, 7 are performed.

The items 5 and 10 are dependent on each other, so they are a BLOCK and there is no specific place to start.

\section{Principal Circuit}

The yellow squares (with + signs) form the principal circuit, that forms the long circuit. The longest circuit is comprised of item 10, 5 . The tearing advice window shows $\mathrm{WS}=0.000$, for both the items i.e. 5 and 10 . The circuit with yellow line is the circuit to be torn. The value 5 is feeded in the mark item 5 window, for identifying the tear. This replaces every mark, wherever tear is required, with number 5 , within the BLOCK.

After Tearing the Circuit and Partitioning
The matrix rearranges itself after tearing the circuit and a new matrix is formed after partitioning. There appears no 5 mark above the diagonal. All the 0 marks are shifted below the diagonal. Hence this is the final matrix obtained (Fig.9.).

\section{Analysis of Category B Activities after Iterations}

The final DSM has all the activities below the diagonal. Item 1, 2, 4, 6, 7, 8, 9 can start immediately as they have no predecessors. This interprets as; Development of Design and Procurement schedule, Selection of Contractor, Use of advance information technology, Review of design by other team members, Small scale physical models/ 3 D drawings, Considerations for site drainage and Considerations for water conservation can be started immediately. The DSM notified rows the gives a series of activities that can be performed. After this Item 3,11,12,10 are the next activities that can start. These activities can be done simultaneously by assigning them to different people i. e. Selection of Subcontractors/ vendors, Preference of methods/ materials for renovation and deconstruction, Consideration for environmentally safe materials/ methods of construction and Concern to reduce scaffolding. Following these, Item 5 can take place i.e. Standardization of design elements.

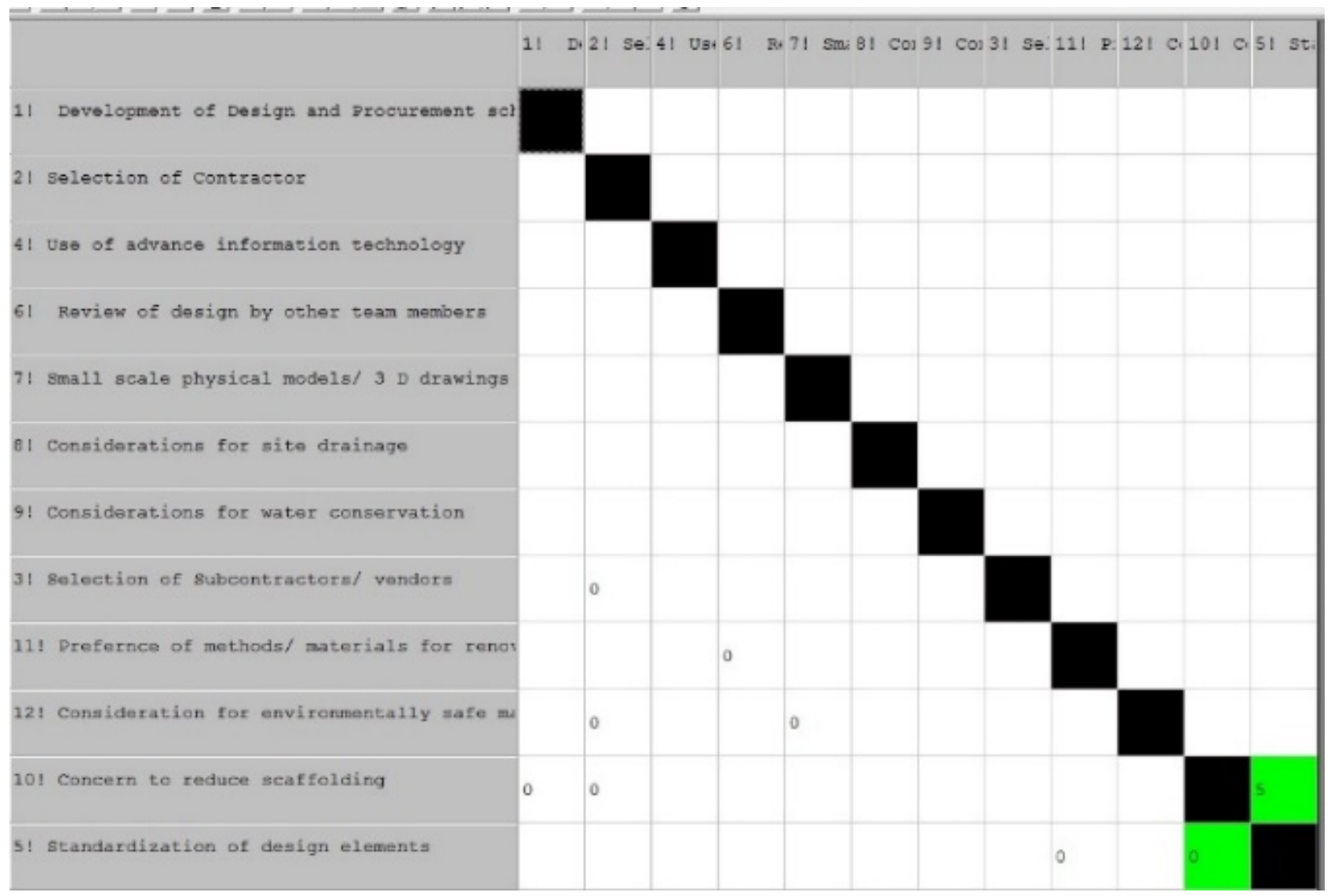

Figure. 9. The final DSM for Category B 


\section{Impact Analysis}

The final DSM is studied for impacts. The purpose of study is to identify the impact of an activity on other activities. The following analysis has been done by the DSM.

- Development of Design and Procurement schedule has an impact on Concern to reduce scaffolding.

- Selection of Contractor has an impact on Selection of Subcontractors/ vendors, Concern to reduce scaffolding and Consideration for environmentally safe materials/ methods of construction.

- Review of design by other team members has an impact on Prefernce of methods/ materials for renovation and deconstruction

- Small scale physical models/ 3 D drawings has an impact on Consideration for environmentally safe materials/ methods of construction

- Preference of methods/ materials for renovation and deconstruction has an impact on Standardization of design elements.

- Concern to reduce scaffolding has an impact on Standardization of design elements.

- Standardization of design elements has an impact on Concern to reduce scaffolding.

- Selection of Subcontractors/ vendors, Use of advance information technology, Considerations for site drainage, Considerations for water conservation and Consideration for environmentally safe materials/ methods of construction have no impact on any other activity.

\section{Parallel Activities Analysis}

The DSM shows the parallel activities also.

- Selection of Subcontractors/ vendors, Concern to reduce scaffolding, Preference of methods/ materials for renovation and deconstruction and Consideration for environmentally safe materials/ methods of construction can be grouped together.

- Development of Design and Procurement schedule, Selection of Contractor, Use of advance information technology, Standardization of design elements, Review of design by other team members, Small scale physical models/ 3 D drawings, Considerations for site drainage and Considerations for water conservation can be grouped together.

\section{Dependent Activities Analysis}

The final DSM has activities which are independent and dependent. These can be planned as worked out. The activities which have been identified by DSM as independent activities are; Development of Design and Procurement schedule, Selection of Contractor, Use of advance information technology, Review of design by other team members, Small scale physical models/ 3 D drawings, Considerations for site drainage and Considerations for water conservation. The dependent activities are as follows:

- Selection of Subcontractors/ vendors depends on Selection of Contractor.

- Standardization of design elements depends on Concern to reduce scaffolding and Preference of methods/ materials for renovation and deconstruction

- Concern to reduce scaffolding depends on Development of Design and Procurement schedule and Selection of Contractor

- Preference of methods/ materials for renovation and deconstruction depends on Review of design by other team members

- Consideration for environmentally safe materials/ methods of construction depends on Selection of Contractor and Small scale physical models/ 3 D drawings.

\section{Application of DSM to Cat- C}

The category $C$ has a set of eight activities (Table 6). The dependency of activities has already been measured by survey. The activities which are least dependent are not considered for making matrix. The remaining dependency chart is as below:

Table 6. List of activities in Category $\mathrm{C}$ and their relationship with other activities

\begin{tabular}{|c|c|c|}
\hline S. No. & Activities & $\begin{array}{l}\text { Depends on } \\
\text { the Activity }\end{array}$ \\
\hline 1 & Field Task Sequencing (CPM) etc. & Independent \\
\hline 2 & Use of temporary material/system on site & 3,7 \\
\hline 3 & Innovation in available equipment & 4,7 \\
\hline 4 & $\begin{array}{l}\text { Freedom to contractors for technical inputs } \\
\text { to improve the construction process }\end{array}$ & Independent \\
\hline 5 & $\begin{array}{l}\text { Use of preassembly in case of adverse } \\
\text { weather }\end{array}$ & 2,4 \\
\hline 6 & $\begin{array}{l}\text { Documentation work of the lessons learned } \\
\text { during the project execution stage }\end{array}$ & Independent \\
\hline 7 & Waste management on site & $2,4,8$ \\
\hline 8 & $\begin{array}{l}\text { Regular inspection/meetings on/off site by } \\
\text { consultants }\end{array}$ & Independent \\
\hline
\end{tabular}

The independent and dependent activities are represented in the Design Structure Matrix (Fig.10.). 


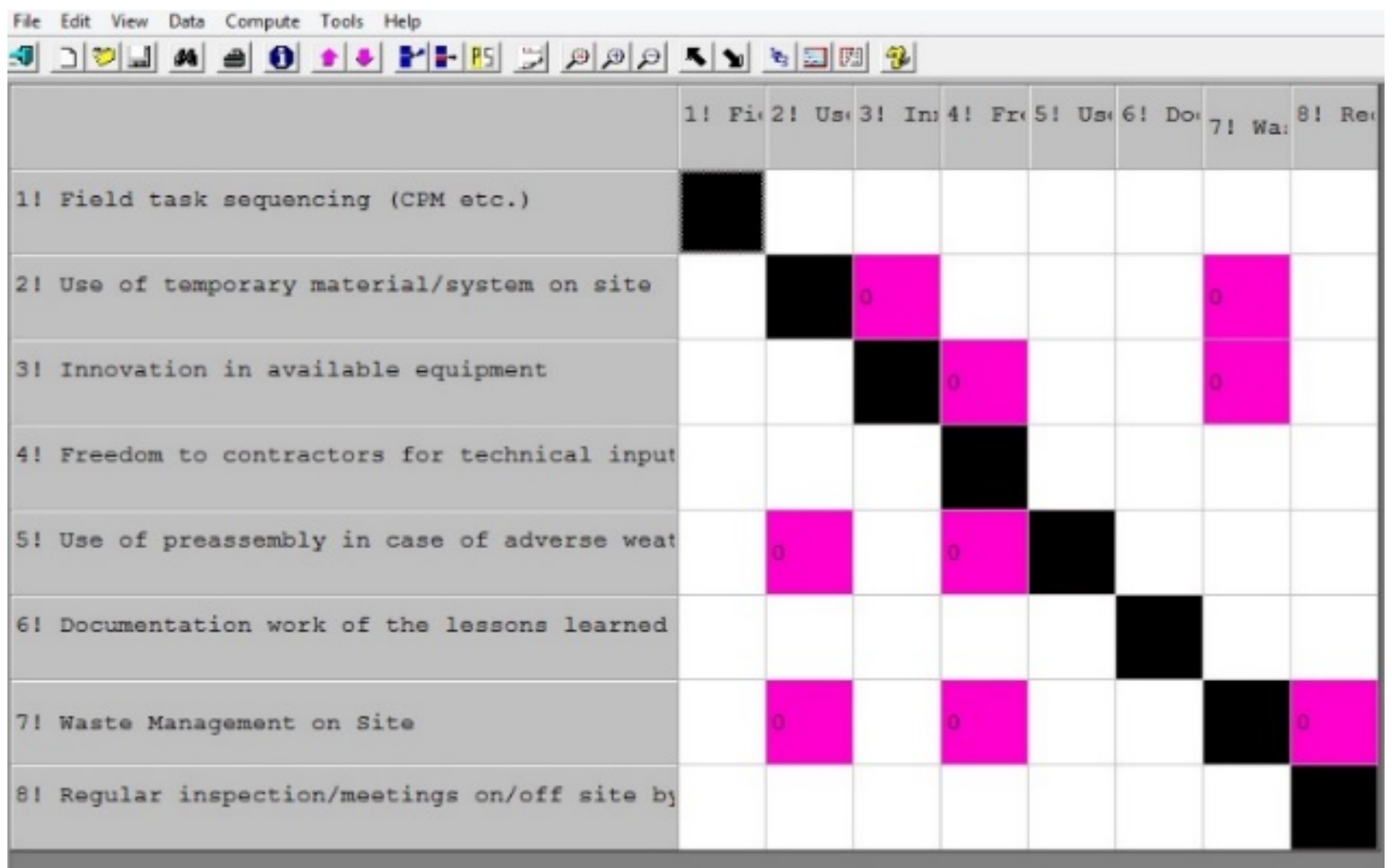

Figure. 10. The original DSM for Category C

The DSM after First Partitioning

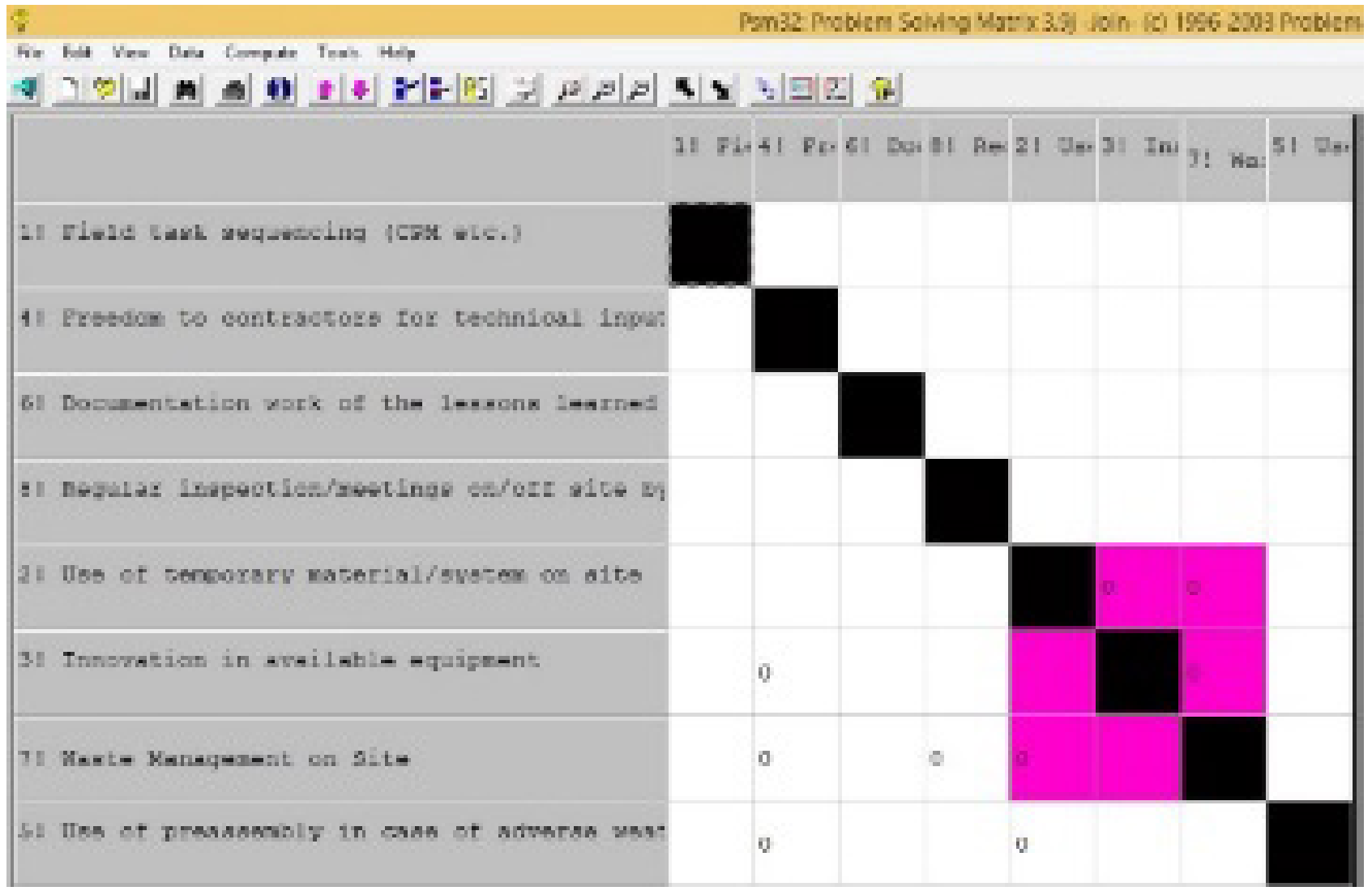

Figure. 11. The DSM showing BlOCK 
The first partitioning rearranges the items and creates a BLOCK of activities that are grouped together (Fig.11.). These are coupled activities. Except the BLOCK all the items appear below the diagonal. The marks above the diagonal show the assumptions. They control the iterations if assumptions are not valid. The marks below the diagonal provide a Critical Path network, if all assumptions are valid.

- The items 1, 4, 6, 8 can be started immediately as they have no predecessors.

- Item 5 can be started after item 2, 4 are performed.

- The items 2, 3 and 7 dependent on each other, so they are a BLOCK and there is no place to start.

\section{Principal Circuit}

The yellow squares (with + signs) form the principal circuit. The longest circuit is comprised of item 2, 3 and 7. The tearing advice window shows WS $=0.000$, for both the items i.e. 2 and 7. The circuit with yellow line is the circuit to be torn. The value 7 is feeded in the mark item 7 window, for identifying the tear. This replaces every mark, wherever tear is required, with number 7 , within the BLOCK.

After Tearing the Circuit and Partitioning
The matrix rearranges itself after tearing the circuit and a new matrix is formed after partitioning. There appears no 7 mark above the diagonal. All the 0 marks are shifted below the diagonal. Hence this is the final matrix obtained (Fig.12.).

\section{Analysis of Category C Activities after Iterations}

The final DSM has all the activities below the diagonal. Item 1, 4, 6, 8 can start immediately as they have no predecessors. This interprets as; Field task sequencing (CPM etc.), Freedom to contractors for technical inputs to improve the construction process, Documentation work of the lessons learned during the project execution stage and Regular inspection/meetings on/off site by consultants can be started immediately. These activities can be done simultaneously by assigning them to different people. The DSM notified rows gives a series of activities that can be performed. After this Item 7, 8, 2 and 5 are the next activities that can start, one after the other. This interprets that the order of different activities, one after the other shall be as follows; Waste management on site, Regular inspection/meetings on/off site by consultants, Use of temporary material/system on site and Use of preassembly in case of adverse weather.

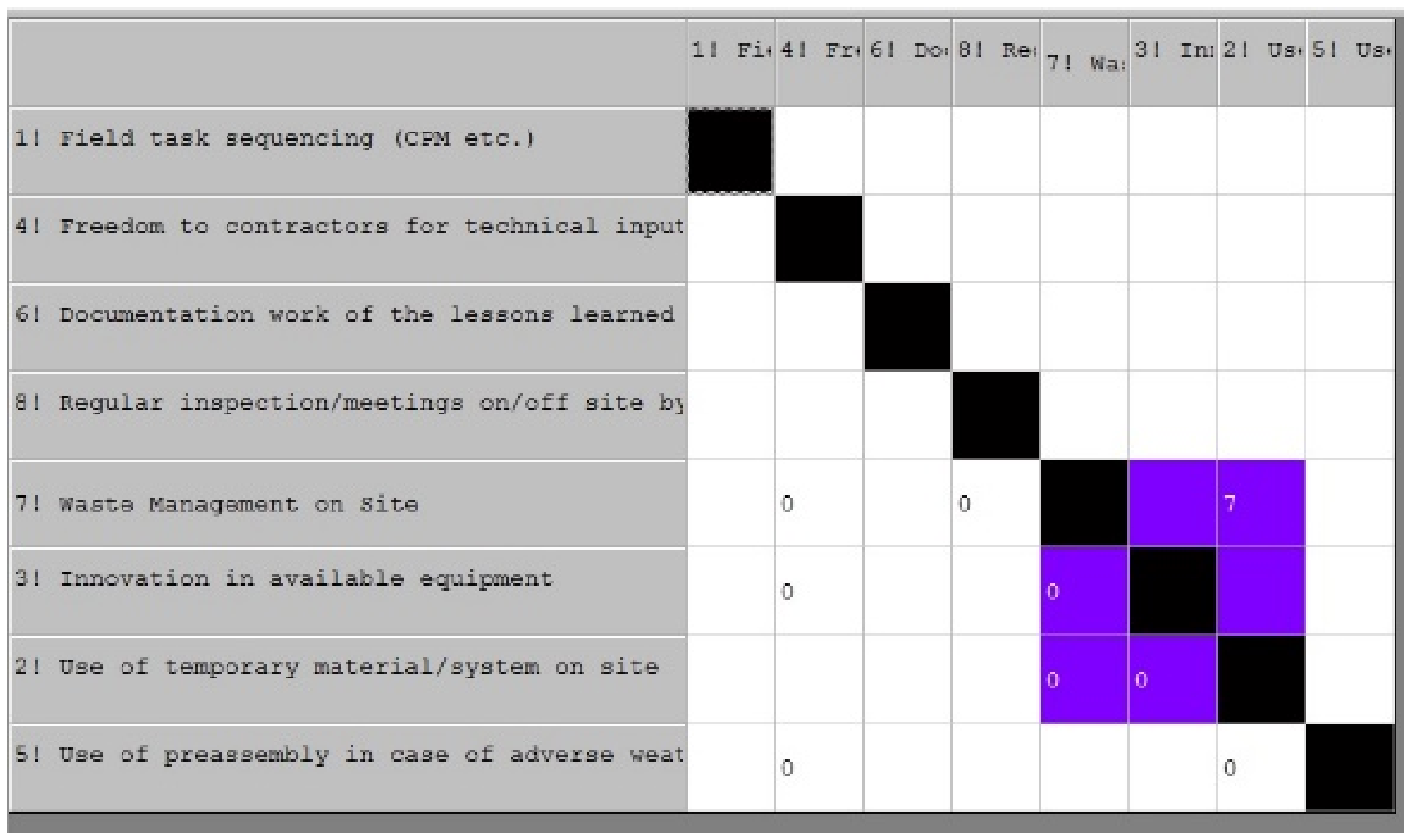

Figure. 12. The final DSM for Category C 


\section{Impact Analysis}

The final DSM is studied for impacts. The purpose of this study is to identify the impact of an activity on other activities. The following analysis has been done by the DSM.

- Freedom to contractors for technical inputs to improve the construction process has an impact on Innovation in available equipment, Use of preassembly in case of adverse weather and Waste management on site.

- Regular inspection/meetings on/off site by consultants has an impact on Waste management on site.

- Waste management on site has an impact on Use of temporary material/system on site and Innovation in available equipment.

- Innovation in available equipment has an impact on Use of temporary material/system on site.

- Use of temporary material/system on site has an impact on Use of preassembly in case of adverse weather.

- Field task sequencing (CPM etc.), Use of preassembly in case of adverse weather and Documentation work of the lessons learned during the project execution stage have no impact on any other activity in the same group.

\section{Parallel Activities Analysis}

The DSM shows the parallel activities also.

- Use of temporary material/system on site and Waste management on site can be grouped together.

- Field task sequencing (CPM etc.), Innovation in available equipment, Freedom to contractors for technical inputs to improve the construction process, Use of preassembly in case of adverse weather, Documentation work of the lessons learned during the project execution stage and Regular inspection/meetings on/off site by consultants can be grouped together.

\section{Dependent Activities Analysis}

The final DSM has activities which are independent and dependent. These can be planned as worked out. The activities which have been identified by DSM as independent activities are; Field task sequencing (CPM etc.), Freedom to contractors for technical inputs to improve the construction process, Documentation work of the lessons learned during the project execution stage, and Regular inspection/meetings on/off site by consultants.

- Waste management on site depends on Regular inspection/meetings on/off site by consultants.

- Innovation in available equipment depends on Freedom to contractors for technical inputs to improve the construction process and Waste management on site.

- Use of temporary material/system on site depends on Innovation in available equipment and Waste management on site.

- Use of preassembly in case of adverse weather depends on Use of temporary material/system on site and Freedom to contractors for technical inputs to improve the construction process.

\section{Results and Discussion}

The results thus obtained were utilized for making simple networks that can be used as MODELS for construction activities, in sequencing the different jobs. The network for the category A, before and after application of DSM is prepared to realize the importance of DSM (Fig.13, 14), as it sorts out the activities and gives a logical sequence of activities to be followed at different stages of a construction project. Selection of Architect, Conducting Surveys and Review and Implementation of Past lessons Learned are identified as Independent activities. These activities can be conducted without waiting for other activities to initiate. Laying out site efficiently depends on selection of Architect and surveys conducted. The Architect is involved in shortlisting of contractors, is responsible for making discussions on how to make construction process easier, selecting the construction methods, selection of recycled materials, working out schedules and simplification of technical specification. The selection of contractors shall lead to selection of construction methods and their suggestions can be incorporated for making construction process easier, recycling and specification selection. They are also involved in preparation of construction schedules. Review and implementation of past lessons learned helps in ease of construction because the errors are not repeated. Discussion on how to make construction process easier would help in selection of appropriate construction methods, recycling practices, and also affect the construction schedule. Laying out site efficiently shall guide way for selection of appropriate construction methods to be adopted.

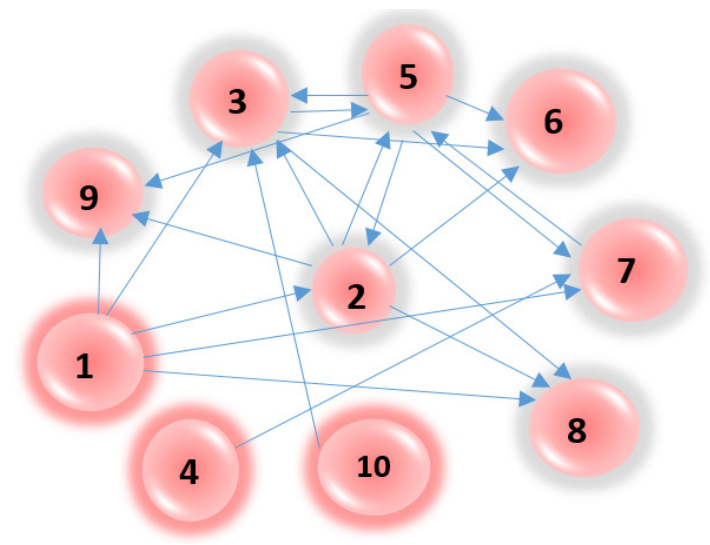

Figure 13. The Network for Category A- Before applying DSM

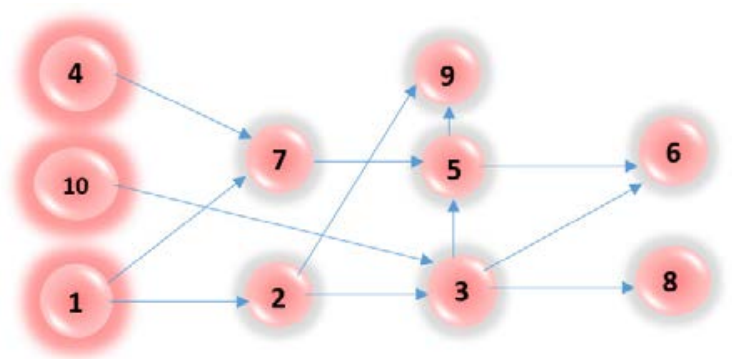

Figure 14. The Network for Category A- After applying DSM 


\begin{tabular}{|c|l|}
\hline \multicolumn{2}{|c|}{ LEGEND } \\
\hline S. No. & \multicolumn{1}{c|}{ Activity } \\
\hline 1 & Selection of Architect \\
\hline 2 & Shortlisting of Contractors \\
\hline 3 & $\begin{array}{l}\text { Discu ssion on how to make construction process } \\
\text { easier }\end{array}$ \\
\hline 4 & Conducting surveys \\
\hline 5 & Selection of Construction methods \\
\hline 6 & Working out Construction Schedule \\
\hline 7 & Laying out site efficiently \\
\hline 8 & Discussion on recycling \\
\hline 9 & Simplification of technical specifications \\
\hline 10 & Review and implementation of past lessons learned \\
\hline
\end{tabular}

Figure 15. The Legend for Category A

The network for the category $\mathrm{B}$, before and after application of DSM is prepared to realize the importance of DSM (Fig. 15, 16), as it sorts out the activities and gives a logical sequence of activities to be followed at different stages of a construction project. Development of Design and Procurement schedule, Selection of Contractor, Use of advance information technology, Review of design by other team members, Small scale physical models/ 3 D drawings, Considerations for site drainage and Considerations for water conservation can be initiated earlier and simultaneously, by the project team members. The selected contractor further collaborates and makes the team with subcontractors/vendors. The planners concern to reduce scaffolding helps in standardization of design elements. It is in the purview of the team to prefer methods/ materials for renovation and deconstruction, which in turn depends on the standardization of the design elements. The two are closely related to each other. Development of Design and Procurement schedule is related to time management which shall also be governed by reduced scaffolding. The selection of the contractor shall lead way for the concern to reduce scaffolding and selection of environmentally safe materials/ methods of construction. If the contractor is concerned for all these factors then only it would be possible to save environment from the pollution and disturbance caused during the construction project. Review of design by other team members brings forward ideas related to methods/ materials for renovation and deconstruction, because of the expertise of the team members in their areas of specialization. Small scale physical models/ 3 D drawings help in analyzing the site scenario during its execution time. Different stages of work and environmentally safe materials and methods of construction can be planned and phases of construction decided which shall help in working on site, without causing much disturbance to the neighbours.

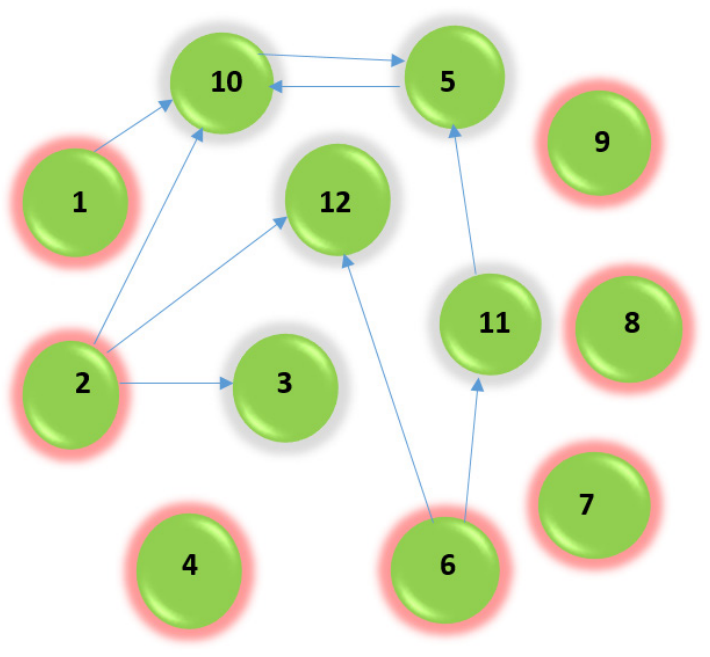

Figure 16. The Network for Category B- Before applying DSM

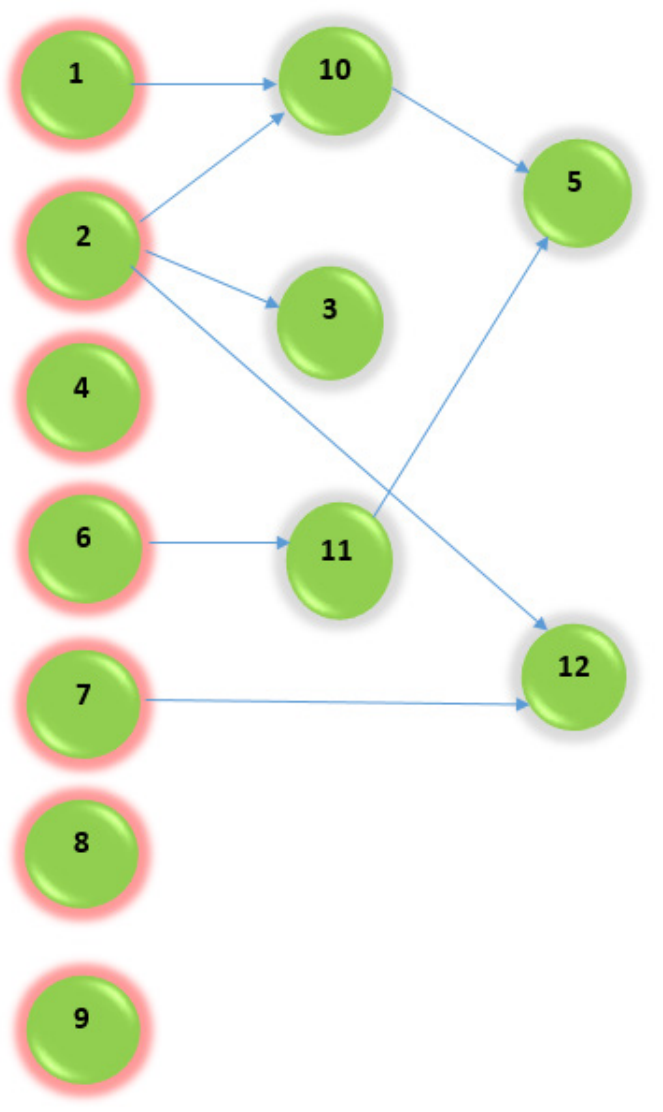

Figure 17. The Network for Category B- After applying DSM 


\begin{tabular}{|c|l|}
\hline \multicolumn{2}{|c|}{ LEGEND } \\
\hline S. No. & \multicolumn{1}{c|}{ Activities } \\
\hline 1 & Development of Design and Procur ement schedule \\
\hline 2 & Selection of Con tractor \\
\hline 3 & Selection of Subcontractors / vendors \\
\hline 4 & Use of advance information technology \\
\hline 5 & Standardization of design elements \\
\hline 6 & Review of design by other team members \\
\hline 7 & Small scale physical models/ 3 D drawings \\
\hline 8 & Considerations for site drainage \\
\hline 9 & Considerations for water conservation \\
\hline 10 & Concern to reduce scaffolding \\
\hline 11 & $\begin{array}{l}\text { Preference of m ethods/ materials for renovation and } \\
\text { deconstruction }\end{array}$ \\
\hline 12 & $\begin{array}{l}\text { Consideration for environmentally safe materials/ } \\
\text { methods of construction }\end{array}$ \\
\hline
\end{tabular}

Figure 18. The Legend for Category B

The network for the category $\mathrm{C}$, before and after application of DSM is prepared to realize the importance of DSM (Fig. 17, 18), as it sorts out the activities and gives a logical sequence of activities to be followed at different stages of a construction project. Field task sequencing (CPM etc.) is to be done at initial stage of work. Freedom to contractors for technical inputs to improve the construction process, Documentation work of the lessons learned during the project execution stage, and Regular inspection/meetings on/off site by consultants shall take place independently during the field operations stage of work. Regular inspection/meetings on/off site by consultants help in controlling and managing waste on site. This helps in regular monitoring of the work and smooth working of the project. If the contractors are given freedom for technical inputs to improve the construction process, it can result in the innovation in available equipment for better working and saving time also, if they use preassembly in case of adverse weather conditions. Waste management on site can also lead to innovation in available equipment to reduce and segregate or manage waste and use of temporary material/system on site.

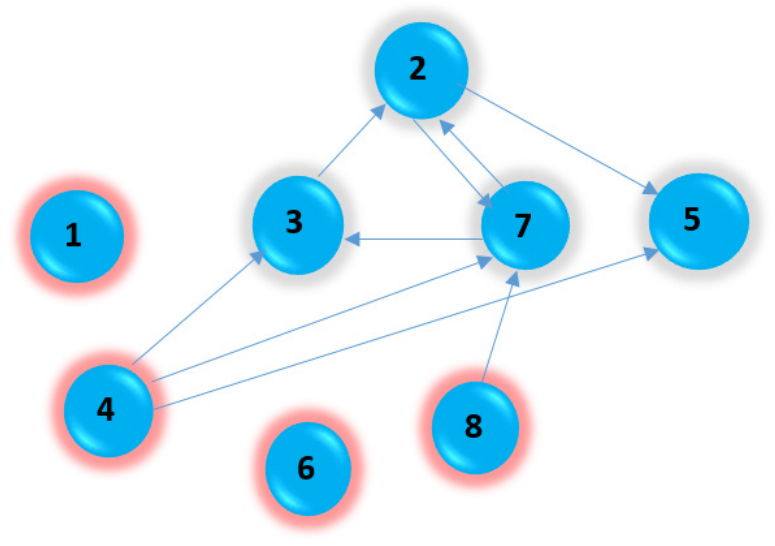

Figure 19. The Network for Category C- Before applying DSM

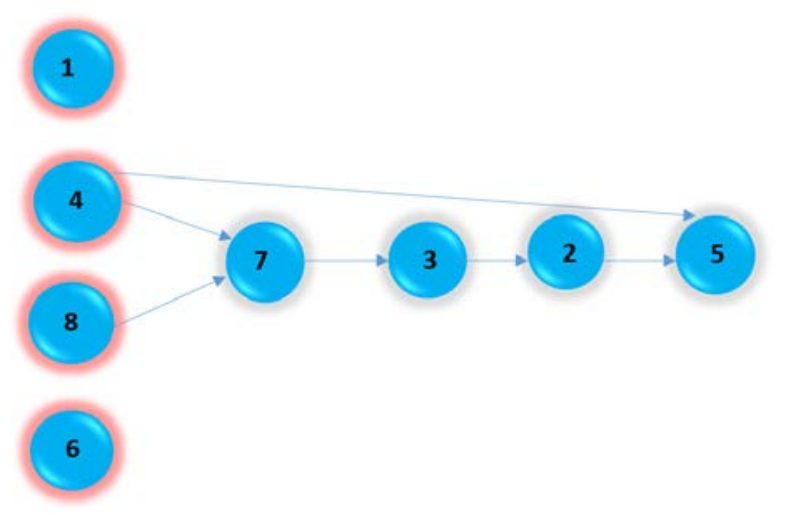

Figure 20. The Network for Category C- After applying DSM

\begin{tabular}{|c|l|}
\hline \multicolumn{2}{|c|}{ LEGEND } \\
\hline S. No. & \multicolumn{1}{c|}{ Activities } \\
\hline 1 & Field Task Sequencing (CPM) etc. \\
\hline 2 & Use of temporary m aterial/system on site \\
\hline 3 & Innovation in available equipment \\
\hline 4 & $\begin{array}{l}\text { Freedom to contractors for technical inputs to } \\
\text { improve the construction process }\end{array}$ \\
\hline 5 & Use of preassembly in case of adverse weather \\
\hline 6 & $\begin{array}{l}\text { Documentation work of the lessons learned during the } \\
\text { project execution stage }\end{array}$ \\
\hline 7 & Waste management on site \\
\hline 8 & Regular inspection/meetings on/off site by consultants \\
\hline
\end{tabular}

Figure 21. The Legend for Category $C$ 


\section{Conclusions}

The Design Structure Matrix is a methodology that can be adopted for complex management problems. The above mentioned study has applied DSM to construction project. The whole process of construction was divided among three categories having thirty activities, in all. The study was then conducted with professionals and the dependency and independency of activities was determined. The data hence collected was utilized for preparing the DSM for the three different categories i.e. Category A- Conceptual Planning Stage, Category B- Design Development Stage and Category C- Field Operations Stage. After partitioning and iterations, the final DSM were obtained. The inferences were drawn from the solved matrix. The independent activities have been listed as Selection of Architect, Conducting Surveys, Review and Implementation of Past lessons Learned, Development of Design and Procurement schedule, Selection of Contractor, Use of advance information technology, Review of design by other team members, Small scale physical models/ 3 D drawings, Considerations for site drainage, Considerations for water conservation, Field task sequencing (CPM etc.), Freedom to contractors for technical inputs to improve the construction process, Documentation work of the lessons learned during the project execution stage and Regular inspection/meetings on/off site by consultants. Rest of the activities are dependent on other activities (as mentioned above). The networks obtained after application of DSM, are resolved and can be followed for smooth working of the project.

\section{REFERENCES}

[1] F.W. H. Wong, D.D.D Saram, Lam, P.T.I and Chan, D.W.M., A compendium of Buildability Issues from the viewpoints of Construction Practitioners, Architectural Science Review, Vol. 49, No. 1, 81-90, 2006.

[2] B. Trigunarsyah, A review of current practice in constructability improvement case studies on construction projects in Indonesia, Construction Management \& Economics, Vol. 22, No. 6, 567-580, 2004.

[3] Constructability: A Primer. (1986). Constr. Industry Inst., The University of Texas at Austin, Austin, Tex., July, 2.

[4] T. E. Glavinich, Improving Constructability during Design phase, Journal of Architectural Eng., Vol. 1, No. 2, 73-76, 1995.

[5] J. T. O’Connor, S E. Rusch and M.J .Schulz, Constructability concepts for Engineering and Procurement, Journal of Construction Engineering And Management Vol. 113, No. 2, 235-248, 1987.

[6] Tatum, C.B. (1987), "Improving Constructability during conceptual planning”, J. of Constr. Eng. And Management, Vol. 113, No.2, 191-207.
[7] Radtke, M. W. (1992) "Model constructability implementation procedures." MS thesis, University of Wisconsin, Madison, Wisc.

[8] Pocock, J. B., Hyun, C.T., Liu, L. Y., and Kim, M. K. (1996). "Relationship between project interaction and performance indicators.” J. Constr. Eng. Manage., 122 (2), 165-176.

[9] Jergeas, G., and Put, J. V. 2001. "Benefits of constructability on construction projects.” J. Constr. Eng. Manage., 127 4, 281-290.

[10] Pulaski, M. H., Horman, M. J., (2005), “Organizing Constructability Knowledge for Design”. J. of Constr. Eng. And Manage. Vol. 131, No. 8, 911-919.

[11] A. A. Yassine, An Introduction to Modelling and Analyzing Complex Product Development Processes Using the Design Structure Matrix (DSM) Method, Journal Urbana, Vol. 51, Issue 9, 1-17, 2004.

[12] D. V. Steward, The Design Structure System: A Method for Managing the Design of Complex Systems, IEEE Transactions on Engineering Management, Vol. 28, 71-74, 1981.

[13] T. R. Browning, Modelling the customer value of product development processes, Proceedings 11th Annual International symposium INCOSE, Melbourne, Australia, July 1-5, 2001b.

[14] M. Danilovic and T. R. Browning, Managing complex product development projects with design structure matrices and domain mapping matrices, International Journal of Project Management, 25, 300-314, 2007.

[15] www.dsmweb.org accessed on 18.8.15.

[16] T. R. Browning, Process Integration Using the Design Structure Matrix, Systems Engineering, Vol. 5, No. 3, 2002.

[17] T.R. Browning, and S.D. Eppinger, Modelling impacts of process architecture on cost and schedule risk in the product development, Lockheed Martin Aeronautics Co., Fort Worth, TX, 2002.

[18] T. R. Browning, Applying the Design Structure Matrix to System Decomposition and Integration Problems: A Review and New Directions, IEEE Transactions on Engineering Management, Vol. 48, No. 3, 292-306, 2001a.

[19] D. L. Grose, Reengineering the Aircraft Design Process, Proceedings of the Fifth AIAA/USAF/NASA/ISSMO Symposium on Multidisciplinary Analysis and Optimization, Panama City Beach, FL, September 7-9, 1994.

[20] D. Sharman and A. A. Yassine, Characterizing Complex Product Architectures, Systems Engineering, 2004.

[21] T. Yu, A. A. Yassine and D. Goldberg, A Generic Algorithm for Developing Modular Product Architectures, Proceedings of the ASME 2003 International Design Engineering Technical Conferences, 15th International Conference on Design Theory and Methodology, September 2-6, Chicago, Illinois, 2003.

[22] S. D. Eppinger, Model-Based approaches to managing concurrent engineering, Journal Engineering Design, Vol.2, 283-290, 1991. 